\title{
STUDY REGARDING THE TECHNICAL TRAINING IN THE MILITARY PENTATHLON AT THE 50 M RACE WITH OBSTACLES
}

\author{
Ioan Sabin SOPA \\ sopa_sabin@yahoo.com \\ Marcel POMOHACI \\ marcelpomohaci@yahoo.com \\ “LUCIAN BLAGA” UNIVERSITY, SIBIU, ROMANIA
}

\begin{abstract}
The following research started from the idea that correcting the crawl swimming style could help improve the performance of military students in the $50 \mathrm{~m}$ swimming with obstacles at the military pentathlon. Alongside with other specialists in the military pentathlon and swimming coaches we have elaborated a scoring grid for every error that can occure in the $50 \mathrm{~m}$ swimming with obstacle event. The methods used for evaluating was the scoring grid errors for $50 \mathrm{~m}$ swimming with obstacles, the observation method and also the experiment method. We had two samples in our research, the first group was the experiment group that was formed by 30 students with the age between 18-22 years old components of the military pentathlon team, and the second group, the control group, formed by 30 students with same age. The results of our investigation showed that the experiment group had improved statistical significant differences compared with the control group proving the necessity of using a scorring grid for the $50 \mathrm{~m}$ obstacle swimming in the military pentathlon.

The conclusions of the investigation showed that through the specific scoring system, the experts' assessment certifies the viability of the new analytical curriculum introduced into student planning program within the experimental group.
\end{abstract}

\section{KEYWORDS:}

Technical testing, military pentathlon, military sport, $50 \mathrm{~m}$ race with obstacles

\section{Introduction}

Testing of technical training through specific parameters: starting technique, obstacle crossing technique $(1,2,3,4)$, the technique of the swimming the distance between the obstacles in the crawl style, the breathing technique, the finishing technique. For the objectivity of assessing the abovementioned parameters we have established in our research a commission made up of 
3 experts (teachers with specialization in swimming, with a minimum 4-year training period), which, according to the scale of appreciation, granted an established a priori note in the system from 1 to 10 . There are many factors determining high physical endurance in young swimmers.

The area of the military pentathlon has developed spectacularly from one edition to the next. "Today, more than 30 nations are present in the circuit of international pentathlon competitions. Most of the time the military pentathlon is included in the World Military Games" (Ene, 2003; Ene-Voiculescu, 2016).

The influences of somatic indices are among them. Some authors closly studied the indices of physical fitness on swimming speed for many years and concluded that these parameters, of swimming technique, directly determine the ability of high performance in swimming (De Mello \& Böhme, 2010; Geladas, Nassis \& Pavlicevic, 2005; Lätt et al., 2010; Morouco et al., 2011; Reis et al., 2010; Strzala \& Tyka, 2009).

The scoring system is elaborated according to the coefficient of the level of execution mistakes, namely: big mistakes, medium mistakes, small mistakes (Table no. 1). Big mistakes are considered by experts as the ones that cause distortions of the fundamental mechanism of the execution technique. Medium mistakes are those that do not distort the fundamental mechanism and can be corrected by practice. Small mistakes are those that do not distort the fundamental mechanism and are secondary mistakes. Other scientific papers discovered that in the center of interest at performance swimmers the adjustment of movement technique to produce a large amount of power and to minimize the resistance is always an important objective (Leblanc et al., 2007;
Seifert et al., 2010). Many researches found out that in analyzing the swimming technique strategies that adapt to rising fatigue and improving resistance during the race and its separate parts is of interest to and useful for coaches (Chatard et al., 2001; Strzala et al., 2005).

The arithmetic mean is recorded by the three experts for each technically verified parameter representing the final individual result for each subject.

\section{Study design}

\subsection{Objectives of the research}

The research objective followed the idea that building a specific scorring grid for errors that occure more frecvent in the $50 \mathrm{~m}$ swimming with obstacles in the military pentathlon we can elaborate a specific program and obtain better results in this event.

\subsection{Research sample}

In our research we used two groups, the first group, the experiment group, was formed by 30 military students with age between 18-22 years old components of the pentathlon military team, the second group, the control group, was formed by 30 military students with the same age between 18-22 years old that practice military physical education.

\subsection{Research method - Testing of} technical training in conditions specific to obstacle swimming on a distance of $50 \mathrm{~m}-$ counter-clock test

We have applied this test to determine to what extent improvement in technique results in increases in performance over the specific conditions of swimming. The test was performed on a counter-clock on a distance of $50 \mathrm{~m}$. The results were recorded in seconds and tenths of a second. 
Table no. 1

The indicative scoring grid according to the typology of error classification

\begin{tabular}{|c|c|c|c|c|}
\hline \multicolumn{2}{|c|}{$\begin{array}{c}\text { Verified } \\
\text { and noted } \\
\text { parame- } \\
\text { ters }\end{array}$} & $\begin{array}{c}\text { Big mistakes } \\
\text { (9-7 points) }\end{array}$ & \multirow{2}{*}{$\begin{array}{l}\text { Medium mistakes } \\
\text { (6-3 points) }\end{array}$} & $\begin{array}{l}\text { Small mistakes } \\
\text { (2-1 points) }\end{array}$ \\
\hline & 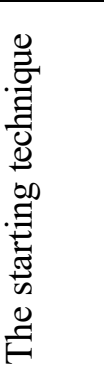 & $\begin{array}{l}\text {-repeted start from the } \\
\text { blockstart before the beep } \\
\text { sound }-9 \text { points } \\
\text { - unbalance forward without } \\
\text { the possibility of pushing } \\
\text { the legs }-8 \text { points } \\
\text { - sliding from the block } \\
\text { start before the start sound } \\
\text { signal }-7 \text { points }\end{array}$ & & $\begin{array}{l}\text {-air way and } \\
\text { position in echer } \\
\text { with folded legs }- \\
2 \text { points } \\
\text { - changing head } \\
\text { position during flight } \\
-1 \text { points }\end{array}$ \\
\hline \multirow{4}{*}{ 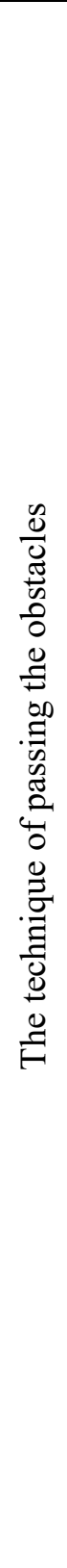 } & 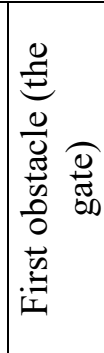 & $\begin{array}{l}\text { - avoiding the obstacle or } \\
\text { slip on the fixed beam - } \\
9 \text { points } \\
\text { - leaving the water after } \\
\text { the obstacle }-8 \text { points } \\
\text { - failing to pass under the } \\
\text { passage under the second } \\
\text { beam }-7 \text { points }\end{array}$ & $\begin{array}{l}\text { - non-coordination of arms for } \\
\text { attacking the first beam }-6 \text { points } \\
\text { - delayed attack of fixed obstacle - } \\
5 \text { points } \\
\text { - to deep jump after the first } \\
\text { obstacle }-4 \text { points } \\
\text { - the absence of optimal impulse } \\
\text { force after the second beam }-3 \text { points }\end{array}$ & $\begin{array}{l}\text {-non- } \\
\text { synchronization of } \\
\text { the frequency of the } \\
\text { arms and legs to the } \\
\text { fixed beam attack - } \\
2 \text { points } \\
\text { - short jump after the } \\
\text { first obstacle - } 1 \text { point }\end{array}$ \\
\hline & 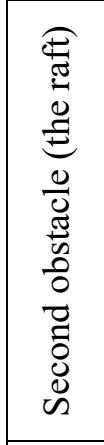 & $\begin{array}{l}\text { - avoiding the obstacle or } \\
\text { insufficient ability to maintain } \\
\text { apnea under the raft and } \\
\text { exit from the lane }-9 \text { points } \\
\text { - non-coordinating when } \\
\text { entering under the raft - } \\
8 \text { points } \\
\text { - lack of work of arms and } \\
\text { legs under the raft }-7 \text { points }\end{array}$ & $\begin{array}{l}\text { - not using the entrance and exit } \\
\text { edges of the obstacle with the arms } \\
-6 \text { points } \\
\text { - not using the entrance and exit } \\
\text { edges of the obstacle with the legs } \\
-5 \text { points } \\
\text { - exit with the wrong arm after the } \\
\text { obstacle }-4 \text { points } \\
\text { - the lack of coordination of arms and } \\
\text { legs under the raft }-3 \text { points }\end{array}$ & $\begin{array}{l}\text { - sliding at the } \\
\text { moment of impulse } \\
\text { at exiting the } \\
\text { obstacle }-2 \text { points } \\
\text { - not using the raft } \\
\text { edge at the obstacle } \\
\text { exit }-1 \text { point }\end{array}$ \\
\hline & 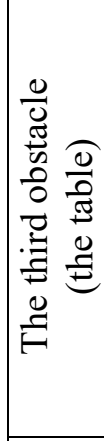 & $\begin{array}{l}\text {-avoiding the obstacle or } \\
\text { the impossibility of } \\
\text { attacking the obstacle - } \\
9 \text { points } \\
\text { - stationary for a long time } \\
\text { on the obstacle }-8 \text { points } \\
\text { - the balanced offset on the } \\
\text { table }-7 \text { points }\end{array}$ & $\begin{array}{l}\text { - non-synchronization of the attack } \\
\text { arm movement with the obstacle - } \\
6 \text { points } \\
\text { - deep jump after the table - } \\
5 \text { points } \\
\text { - the absence of coordination of } \\
\text { the preparatory step for the jump - } \\
4 \text { points } \\
\text { - sliding on the table when } \\
\text { jumping }-3 \text { points }\end{array}$ & $\begin{array}{l}\text {-insufficient impulse } \\
\text { when climbing on } \\
\text { the table }-2 \text { points } \\
\text { - non-use of the arms } \\
\text { at the time of the } \\
\text { obstacle attack - } \\
2 \text { points }\end{array}$ \\
\hline & 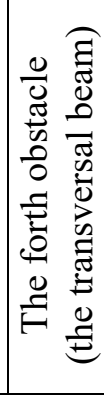 & $\begin{array}{l}\text { - stopping or avoiding an } \\
\text { obstacle }-9 \text { points } \\
- \text { the non-existence of the } \\
\text { attack phase }-8 \text { points } \\
\text { - non-use of impulse force } \\
\text { at the exit of the obstacle - } \\
7 \text { points }\end{array}$ & $\begin{array}{l}\text { - lack of coordination of arms with } \\
\text { legs at the entrance of obstacle } \\
-6 \text { points } \\
- \text { non-use of the obstacle }-5 \text { points } \\
- \text { lack of coordination of breathing } \\
\text { with arm movement }-4 \text { points } \\
\text { - lack of coordination of breathing } \\
\text { with the movement of the legs - } \\
3 \text { points }\end{array}$ & $\begin{array}{l}- \text { inefficient } \\
\text { movement of the } \\
\text { body when leaving } \\
\text { the obstacle-2 points } \\
\text { - sliding of the foot } \\
\text { at the moment of } \\
\text { impulse exit - } \\
1 \text { points }\end{array}$ \\
\hline
\end{tabular}




\begin{tabular}{|c|c|c|c|c|}
\hline \multicolumn{2}{|c|}{\begin{tabular}{|c|}
$\begin{array}{c}\text { Verified } \\
\text { and noted } \\
\text { parame- } \\
\text { ters }\end{array}$ \\
\end{tabular}} & $\begin{array}{l}\text { Big mistakes } \\
\text { (9-7 points) }\end{array}$ & \multirow{2}{*}{$\begin{array}{l}\text { Medium mistakes } \\
\text { (6-3 points) } \\
\text { - the acceleration of movements of } \\
\text { the feet (too small step) and } \\
\text { inefficient }-6 \text { points } \\
\text { - stiffness of the ankle and the } \\
\text { knee joint }-5 \text { points } \\
\text { - leg movements are not } \\
\text { synchronized from the triple } \\
\text { flexion chain }-4 \text { points } \\
\text { - feet out too much of the water - } \\
3 \text { points }\end{array}$} & \multirow{2}{*}{$\begin{array}{l}\text { Small mistakes } \\
\text { (2-1 points) } \\
\text { - the sole of the legs } \\
\text { isn't enough rotated } \\
\text { in the inside - } \\
2 \text { points } \\
\text {-knee articulations } \\
\text { do not perform } \\
\text { extension in the } \\
\text { upward phase - } \\
1 \text { point }\end{array}$} \\
\hline \multirow{4}{*}{ 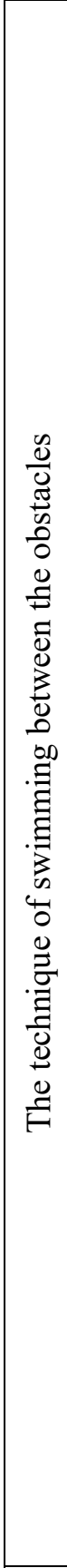 } & 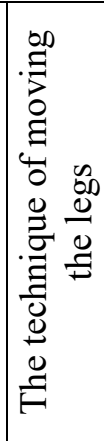 & $\begin{array}{l}\text { - moving the legs with } \\
\text { strained and in extension - } \\
9 \text { points } \\
- \text { the shear movement of } \\
\text { the legs produced in front } \\
-8 \text { points } \\
\text { - entry into the preparatory } \\
\text { stage with extended legs - } \\
7 \text { points }\end{array}$ & & \\
\hline & 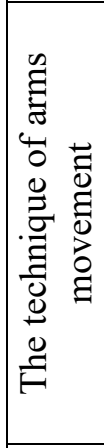 & $\begin{array}{l}\text { - zigzag movement of the } \\
\text { arms }-9 \text { points } \\
\text { - the arm is shuffled wry } \\
\text { forward }-8 \text { points } \\
\text {-rowing with the extended } \\
\text { arm }-7 \text { points }\end{array}$ & $\begin{array}{l}\text {-arms bent too much underwater- } \\
6 \text { points } \\
\text { - underwater movement is too } \\
\text { short }-5 \text { points } \\
- \text { the arms fall into the water or are } \\
\text { stretched beyond the median line } \\
\text { of the body }-4 \text { points } \\
\text { - shortening the rowing by pulling } \\
\text { out of the water before the full } \\
\text { stretch of the arm }-3 \text { points. }\end{array}$ & $\begin{array}{l}\text { - underwater motion } \\
\text { fingers are not } \\
\text { stretched and bonded } \\
-2 \text { points } \\
\text {-the hand slaps the } \\
\text { water }-1 \text { point }\end{array}$ \\
\hline & 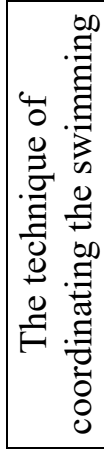 & $\begin{array}{l}\text { - pauses in the movement } \\
\text { of the arms }-9 \text { points } \\
\text { - movement of the legs } \\
\text { irregularly }-8 \text { points } \\
\text { - non-synchronization of } \\
\text { the arms cycle with } \\
\text { breathing and movement } \\
\text { of the legs }-7 \text { points }\end{array}$ & $\begin{array}{l}\text { - the front arm slows start of } \\
\text { traction }-6 \text { points } \\
\text { - not finishing the arm movement } \\
\text { in the air phase }-5 \text { points } \\
\text { - moving the arm forward on the } \\
\text { opposite side of the breathed part - } \\
4 \text { points } \\
\text {-inspiration - expiration without } \\
\text { synchronizing with the movement } \\
\text { of the legs }-3 \text { points }\end{array}$ & $\begin{array}{l}- \text { leg movement is } \\
\text { short and irregular - } \\
2 \text { points } \\
\text { - at the entrance into } \\
\text { the water the full } \\
\text { extension of the } \\
\text { forward arm }-1 \text { point }\end{array}$ \\
\hline & 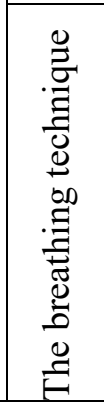 & $\begin{array}{l}\text { - complete respiration }- \\
9 \text { points } \\
- \text { in synchronization of } \\
\text { inspiration with an } \\
\text { expiration }-8 \text { points } \\
\text { - no expiration in water - } \\
7 \text { points }\end{array}$ & $\begin{array}{l}\text { - the head sinks too much for the } \\
\text { expiration }-6 \text { points } \\
\text { - turning the head in inspiration } \\
\text { without the movement of the } \\
\text { shoulders }-5 \text { points } \\
\text { - the absence of the twisting } \\
\text { movement in inspiration }-4 \text { points } \\
\text { - continuous exhalation outside the } \\
\text { water }-3 \text { points }\end{array}$ & $\begin{array}{l}\text { - the head rises, the } \\
\text { lower train sinks - } \\
2 \text { points } \\
\text { - decrease/increase } \\
\text { of the duration of } \\
\text { inspiration }-1 \text { point }\end{array}$ \\
\hline & 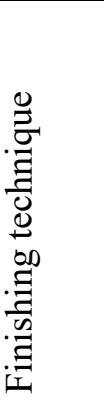 & $\begin{array}{l}\text {-in the attack phase, } \\
\text { stopping arm movements - } \\
9 \text { points } \\
\text {-in the attack phase the } \\
\text { stopping of the leg } \\
\text { movements }-8 \text { points } \\
\text { - the absence of respiration } \\
\text { during the attack phase - } \\
7 \text { points. }\end{array}$ & $\begin{array}{l}\text { - attack of the wall with a flexed } \\
\text { elbow }-6 \text { points } \\
\text { - the sliding is not held straight } \\
\text { ahead before the finish }-5 \text { points } \\
\text { - non-coordination of the arm } \\
\text { movements }-4 \text { points } \\
\text { - non-synchronization of leg } \\
\text { movements - } 3 \text { points }\end{array}$ & $\begin{array}{l}\text {-lifting the head } \\
\text { before reaching the } \\
\text { wall with the arms - } \\
2 \text { points } \\
\text { - extension of the } \\
\text { sliding phase to } \\
\text { completion, reaching } \\
\text { the wall - } 1 \text { point }\end{array}$ \\
\hline
\end{tabular}




\subsection{The technique of crawl}

The crawl style on the chest is the fastest method and has developed from the "dog style" swimming, in which the arms and legs alternately with water without getting out. The process also derives from "loose", to which the feet perform a genre of shearing. The arms perform an increased traction motion toward the "dog style" swimming. The position of the body in the water to the modern craw is lying on the chest with its extended legs. The forwardlooking head is submerged in water up close to eyebrow, and the chest is raised near the surface. The movement of the legs is alternate and is carried out vertically. From the point of view of motion and biomechanics, the co-femoral joint is the control center.

To increase the leg support surface downward, the foot plant rotates inwards (close peaks). Each leg has two phases to execute: one descending (top-down) and one ascending (bottom-up).

a) Downward phase (down). The thigh flexes down and the calf is delayed due to water pressure, causing flexion in the knee joint. At the end of the movement, while the thigh starts moving upward, the calf continues the movement downward until the knee is fully stretched.

b) Upward Phase (Up). The thigh flexes vertically, followed by the calf. Water pressure on the calf determines the extension of the knee. At the end of the movement, while the thigh moves down, the chest continues the movement in the vertical plane, the knees bend again. Calf and foot sole complete pressure on the water without getting out of the water.

c) Both legs move alternatelyuniformly, without deviating them from the median axis of the body. The upward and downward movements are carried out at the same pace. The "step" (the distance between the upper and lower points of the leg movement) is $25-30 \mathrm{~cm}$ and varies according to the size and power of the swimmer, as well as the swimming speed.
The movement of the arms is cyclical-alternative. The superior member segments on the water are the front of the hand and forearm, the fingers being extended and close during the rowing, the slightly flexed palm facing perpendicular to the forward direction. On advancing, the movement of the arms is approximately 2 to 1 in relation to the movement of the legs. In the cycle of an arm movement, we distinguish two phases: one active, underwater, and one passive, preparatory, aerial.

a) The underwater phase is conditionally composed of traction and a pushing phase. It starts from the position of the raft, with the arm stretched forward, along with the shoulder line, then passing under the body, close to the median axis of the body. The arm presses down, continuing the elbow bending motion (T1-T2), then moves to the pushing moment, which is performed by the boom extension (T3-T4). At the moment of pushing, the palm is facing up, near the thigh. Passing is done quickly, without pause, in the air phase (T5).

b) Air Phase. Through a flexion from the elbow joint (T1) the arm is taken out from the water (T2); the elbow stays all the way over the water as the highest point, while the forearm and the relaxed hand perform a slight external rotation of the elbow joint (T3). The hand enters the water on the shoulder line, then stretches (T4).

c) The movement of both arms is alternating. Movement over the water runs in less time than under water. The traction of an arm corresponds to the other's pushing forward, and the pushing and stretching phases to the front. Breathing is related to the movement of the arms. While one gets out of the water to be carried forward, the head returns to the same side for inspiration. After inspiration the head resumes its old position, face down, followed by strong exhalation. Meanwhile, that arm ends the airway and begins the underwater phase. With the underwater phase, expiration also ends. First, it expires only on the same side (two, arms), and 
alternate (three arms) breathing, where the expiration is extended over a complete cycle of arms, the inspiration alternating on one side and on other.

Coordination. On one arm cycle six foot movements are executed, ie three beats up and three down. The movement of the feet is carried out without interruption.

\subsubsection{Method of crawl style learning}

The optimal methodic line in learning a correct technique is systematic work, based on respect for the principles of learning. New skills proposed to be taught will meet the conditions of dynamic stereotyping only if their transfer is positive. This transfer can be done under the circumstances in which previous skills have been appropriated. For this reason, we recommend increased attention during learning. From the methodological point of view, fundamental errors will be eliminated those that substantially modify the technical mechanism of execution.

\section{A. Learning to move legs and breath Exercises on land:}

1) Seated with arms stretched out and hands supported in the back, cawl movement is made, knees stretched, legs turned inward, relaxed.

2) Lying down in front of the same move.

Exercises on land have no purpose other than to accustom the students to the movement as a whole. It is not advisable to execute them for a longer time, because the movement acquires a character other than that under the influence of water.

Exercises in water:

1) Exercise feet lying on the back in small water

2) Exercise of feet with partner in small water.

3) The exercise of feet at the wall.

For wall exercises, one hand will catch the edge of the swimming pool, the bar or the break-wave, and the other rests against the pool with the palm at the wall, the fingers pointing downward. In this way, the body can best maintain the surface of the water in a stretched position.

4) The exercise of feet from the raft position with respiration under the water. Since the correct execution of the floating position is a prerequisite for this exercise, repeat the floating position.

5) The exercise of breathing with a partner or wall without foot movements. Inspiration will be done quickly, by mouth, raising your head from the water, and exhaling in a long time, forced, on your mouth and nose in the water. The ratio between inspiration and expiration should be approximately 1 to 2 . It will be watched that the expiration is entirely under water.

6) Breathing exercise with a partner or wall with side inspiration. In this exercise, not the shoulder, but the head turns to one side. Exercise will be executed to both parts.

7) The exercise of breathing with a partner or wall, with the movement of the legs. In six descending movements (downwards) one briefly, laterally, inspires about two beats and exits once in the water for about four beats. Students will be accustomed to counting beatings from the beginning, which is not easy. This exercise should be repeated for a longer time and without breaks (1-3 minutes).

8) The exercise of feet with the raft. The raft or the training pad is called board made especially for the training of foot movements. It can be replaced with a plastic pillow, ball or flotation ring, generally with anybody that floats well and does not pose a risk of injury to students. During this exercise, emphasis will be placed both on the movement of the legs and on the breathing. Both must be performed rhythmically.

9) The exercise of legs from the floating position with arms stretched out and with breathing technique.

10) The exercise of legs from the floating position, with the arms attached to the body, and with breathing technique. 
11) The exercise of legs from the floating position with arms crossed in the back with breathing technique.

12) The exercise of legs at the edge of the pool with the body half out (supported by the arms), the feet performing the movement very deep.

Methodological indication:

Exercises 10, 11, 12 aim specifically at developing leg muscles and performing a powerful, effective movement.

13) Swimming with crawl legs specific technique, with and without the raft, on progressively increased distances $(20 \mathrm{~m}$, $200 \mathrm{~m}, 300 \mathrm{~m}$ ) with a focus on breathing.

\section{B. Learning the arm movement} technique

1) Performing the movement of arms on land, first with an arm, then with both alternatively, the trunk being bent forward. Just as in foot exercises on land and on the arms, we draw attention that subjects only become familiar with the movement as a whole and not the training.

2) Exercises of arms in water to the waist, with and without breathing.

3) Exercises of arms in water to the waist, with a specific breathing technique. Breathing on both sides.

4) Exercises with arms and breathing from the floating position, with a partner, the performer being supported by the legs.

5) Breathless exercises with no partner and no movement of the legs.

\section{Learning the coordination}

1) Swimming without breathing technique. Coordinating arm and leg movements are a problem for beginners. The feet perform three movements up and down, and the arms only a complete movement. While one arm performs a strong thrust movement, the other is moved forward, relaxed.

In order not to complicate this rather complicated succession of breathing movements, breathing exercises will begin at first, putting the head in water without sinking too much. The distances to swim without breath will gradually increase. Also for helping conditions, the subjects will initially perform the floating position and leg movement with their arms stretched forward, and after they have traveled a small distance, they can start with the movement of their arms.

2) Swimming coordinated with breathing. As with the previous exercise, students will start from the wall only with the movement of their feet but with breathing technique, after which they will try to introduce the movement of the arms. The distances at the beginning will be short, with 1-2 breaths, increasing as the coordination is appropriated.

\section{Correcting the mistakes}

The technique described above can be considered perfect. In the following, we will try to analyze the most common mistakes, together with the association of the methodical indications regarding their correction and removal.

a) Breathing errors.

We have to give them priority because bad breathing technique prevents the correct learning of the crawl process, generating a number of other mistakes.

The fires mistake: Do not exhale in water or expiration is incomplete. The student is not able to overcome the water pressure when he is underwater and uses the short time that the mouth and nose are above the water for both exhalation and inspiration. That is why there is no time for a profound inspiration. Due to lack of air, the student swallows water, the movements become hurried and contracted, which also increases the rhythm of the arms (the underwater movement of the arms is interrupted, sometimes the head is kept crisp over the water).

\subsection{Methodological indication}

Due to the insufficient repetition of submersion and expiration under water, they must be repeated systematically. The emphasis 
will be on a complete underwater exhalation, which ends when the arm on the breathing side completes the pushing phase under water.

The second mistake: the head sinks too much for the expiration.

Third mistake: for inspiration, not only the head but also the shoulders, returns to the body, a twisting movement.

Method of removing this mistake:

- Relaxation exercises on land;

- Breathing exercises at the edge of the swimming pool, in lying support or with a partner, where the inspirational head will return, the shoulders remaining in the horizontal position;

- immersing only the face in water;

- feet exercises with hands together to the body or to the back, whereby the performer is forced to keep his head higher.

b) Main mistakes of leg movement

The first mistake: hurrying the foot movements (too small a step) and ineffective.

Third mistake: The sole of the feet are not sufficiently rotated inwards.

Second mistake: stiffness of the ankle and knee joints.

Removing these mistakes:

- relaxation of the knees and ankles by exercises on land and water;

- feat movement with raft exercises with raft accentuating foot movement and step increase (distance between upper and lower motion).

Fourth mistake: The leg movements do not have the starting point in the hips, the thighs do not move away from each other in the sagittal plane. Cafes perform knee-knocking actively, although they must passively move the thigh.

Fifth mistake: the knees do not stretch to the upward movement.

Removing these mistakes:

- the movement of the legs and especially of the thighs is explained and demonstrated once again;

- wall and raft exercise with permanent correction;

- if the correction is not done, a partner will press down on the knee;
- performing the knee-high movement.

Sixth mistake: Feet are out too much from the water

Removing this mistake:

- it is usually sufficient to say not to sprinkle the water;

- lifting the head higher.

c) Major mistakes of arm movement

First mistake: The arm bends too much to the underwater movement, passing the palm far beyond the median line of the body, causing an exaggerated rotation on the longitudinal axis of the body.

Ending this mistake:

- strengthening arm force through exercise on land and swimming;

- the main indication must include not to cross the median line of the body, and the head should remain in the usual position without being influenced by the action of the arms;

- executing the movement of the arms with the eyes open underwater to check the path of the palms.

The second mistake: on the underwater movement the fingers are not stretched and together.

Ending this mistake:

- repeatedly drawing attention to that mistake.

- Third mistake: zigzag movement of the arms due to water resistance.

Removing this mistake:

- Improving arm strength by exercising on land and water;

- observing that the arms are not too stretched under the underwater movement (in this case, it is recommended to bend the elbows).

Fourth mistake: Underwater movement is too short. Due to lack of force or negligence, the student only performs part of the pushing phase, raising the arm to the chest. If it expires too soon, quickly and incompletely, the swimmer seeks to finish the underwater movement of the arms as soon as possible to lift his mouth over the water to inspire. The movements become hasty and tense. 
Removing this mistake:

- exercises to strengthen the muscles of the arms;

- emphasizing the pushing of the arms during swimming;

- The swimmer will be requested to touch the thigh with his thumb, thereby creating the possibility of controlling his own movement. If faulty breathing causes this mistake, the breathing exercises will be repeated again. If it is the case, it will start later, so that it can be completed with the arm movement.

Mistake: Your arm is going forward crisp, and the alternation between contraction (underwater) and relaxation (above water) is not right.

Removing this mistake:

- moving the arms forward will be made conscious, relaxed by shaking the forearm after it is removed from the water;

- the arm should plow in front (the elbow being the highest point) without lifting the forearm above the elbow.

The mistake is: Your hand sheds water instead of going in and then pushing it into the water.

Removing this mistake:

- relaxation of shoulder and arm joints;

- tracking the palm of your hand from the water inlet to the full stretch of the arm forward by keeping your eyes open in the water.

Fourth mistake: The arms fall into the water, or they are pushed past the midline of the body, giving it a twisting motion and causing a winding stroke.

Removing this mistake:

- it will give the indication to put an exaggerated side of the hand in the water.

d) Main mistakes in coordination

First mistake: pauses in arm movement. Sometimes the front arm delays the start of the traction until the other almost terminates the air phase (forward).

Removing this mistake:

- repeating the movement of the arms, at the beginning separately, then connected with the movement of the legs.
Second mistake: Leg movement is too low and hasty. If more than six beats are carried out in an arm movement, the legs work inefficiently. If, however, there is a good advance with the eight-foot rhythm of an arm's cycle, it should not be considered a mistake.

Third mistake: the movement of the legs is irregular. Often, the movement of the arms affects the legs, in the sense that when the arm is pulled forward on the side where it is taken the breath, the body is twisted on the same side, which causes the movement of the leg or a beating "step", but much larger.

Removing this mistake:

- feet exercises at the edge of the breathing pool, counting up to six (at a single breath);

- exercises with the raft, breathing, counting up to six.

If the rhythm of the legs is reinforced, the introduction of the arm movement is no longer a problem.

\subsection{The start for the crawl style}

The start for the crawl style, dolphin and brass style are performed by a jump on the block start. At the start technique, we distinguish 6 phases:

1. Starting position.

2. Swinging and pushing the arms.

3. Flight through the air (above the water).

4. Entering the water.

5. Swimming underwater.

6. Exit to the water surface.

\section{Starting position}

At the starter's invitation, the swimmer moves to the edge of the block start facing the pool, grasping the edge of the block with his fingers, the legs approximately at the width of the shoulders. To get the edge of the block as good as possible, the tips will be oriented inward. Afterwards, the swimmer leans forward with his knees slightly bent, his arms down, his head up, his forehead. The weight of the body is passed to the tips. 
2. Swinging and pushing the arms

At the starter signal (whistle, pistol or verbal click), the swimmer responds as follows: leaning forward, the center of gravity of the body is passed forward, outside the support base, simultaneously with the vigorous turning of the arms forward, up and down lateral, knee bending. As the arms come back to the front, a powerful push of the legs is carried out, helped by the arm and the upward movement of the head. The swim is forward, parallel to the surface of the water.

\section{Flight through the air}

In the first part of the flight through the air, the body has a slight extension, and in the second part, it passes into a slight flexion, thus preparing for entry into the water. The start of the crawl and dolphin processes has a lower flight path, while on the brass it is higher. Differentiation is determined by the technique of the other moments of the start. During the flight through the air, there is a deep inspiration.

\section{Entering the water}

To maintain the speed of the body imprinted by moving the arms and pushing the legs, the entrance into the water must be oblique, the arms extended in the extension of the body (chin head in the chest, framed by the arms), the body and legs stretched out. The angle of entry into the water to crawl and dolphin is small enough $15-25^{\circ}$, to avoid submersion under water more than $60-80 \mathrm{~cm}$.

\section{Swimming underwater}

At crawl and dolphin underwater is done in the first part with the body well stretched, and with the loss of the initial speed begins the strong movement of the legs, simultaneously with the expiration. At this point, the slight lift of the head, as well as the position of the arms, determine the surface exit. From the floating underwater, the arms perform a large, dolphin-like movement. The palms execute the prolonged pushing moment, surpassing the shoulder, chest, abdomen, and hips. In this position, the swimmer interposes a short pause to use the speed of the arm movement. Concurrently with the forwarding of the arms in the initial position, the legs are quenched and propelled, so that, when the arms have reached the head, the legs are again stretched out.

\section{Exit to the water surface}

The moment the body is brought back to the surface of the water due to the movements of the legs and starts the movements of the arms.

\section{Results}

Testing the technical training in the conditions of the $50 \mathrm{~m}$ swimming test with obstacles specific to the military pentathlon, in our research highlighted the level of this training both at the initial and at the end of the research. We applied this technique of testing the technical training to highlight the progress made by the subjects of the experimental sample under the conditions of the implementation of the new analytical program in the military physical education discipline. Testing of technical training through specific parameters was carried out both at the beginning of the experiment (initial testing - experimental stage 1, Table no. 2) and at the end of the experiment (final test - experimental test 2 , Table no. 3). Using the scoring system adopted by the three experts (Table no. 1), the research results recorded values for each parameter tested at both the control sample and the experimental sample at all times of the research. 
Table no. 2

Comparative analysis of the results of the test of the technical training at initial testing

\begin{tabular}{|c|c|c|c|}
\hline \multirow{2}{*}{\multicolumn{2}{|c|}{ Researched parameters }} & \multirow{3}{*}{$\begin{array}{l}\text { Control group } \\
\begin{array}{c}\bar{X} \\
\end{array}\end{array}$} & \multirow{3}{*}{$\begin{array}{c}\begin{array}{c}\text { Experiment } \\
\text { group }\end{array} \\
\begin{array}{c}\text { Grade obtained } \\
\bar{X}\end{array} \\
\end{array}$} \\
\hline & & & \\
\hline \multirow{2}{*}{\multicolumn{2}{|c|}{ Starting technique }} & & \\
\hline & & 6,5 & 6,6 \\
\hline \multirow{4}{*}{$\begin{array}{l}\text { The technique of } \\
\text { passing the obstacles }\end{array}$} & Obst. I & 5,4 & 5,8 \\
\hline & Obst. II & 6,2 & 6,4 \\
\hline & Obst. III & 6,6 & 6,2 \\
\hline & Obst. IV & 5,4 & 5,2 \\
\hline \multirow{3}{*}{$\begin{array}{c}\text { The technique of } \\
\text { swimming between } \\
\text { obstacles }\end{array}$} & The movement of leg technique & 6,7 & 6,8 \\
\hline & The movement of arms technique & 6,9 & 7,0 \\
\hline & $\begin{array}{l}\text { The technique of coordinated } \\
\text { swimming }\end{array}$ & 6,8 & 6,9 \\
\hline \multirow{2}{*}{\multicolumn{2}{|c|}{$\begin{array}{l}\text { The breathing technique } \\
\text { The finishing technique }\end{array}$}} & 5,4 & 5,5 \\
\hline & & 5,5 & 5,5 \\
\hline
\end{tabular}

If at the initial testing, the subjects of the two samples recorded relatively equal values of the arithmetic mean of most parameters tested in the technical training, ranging between 5.4-6.9 for the control group, for the experimental group the arithmetic mean and the marks given by the three experts were between 5.2-7.0. At the end of the research, the recorded results showed that the arithmetic averages recorded by the three experts (Table no. 3) were improved results in favor of the experimental group.
Thus, the arithmetic progression of the results recorded at the end of the research showed scores values of the average between 5.8-7.4 for the experiment group. The experimental group recorded arithmetic means values in this test ranging from 7.5 to 10 . The difference in the calculation of the statistical significance between the averages obtained in the final test between the two groups is between the minimum scaling values of 1.7 and 2.6 in favor of the experimental group.

Table no. 3

Comparative analysis of the results of the technical training test at final testing

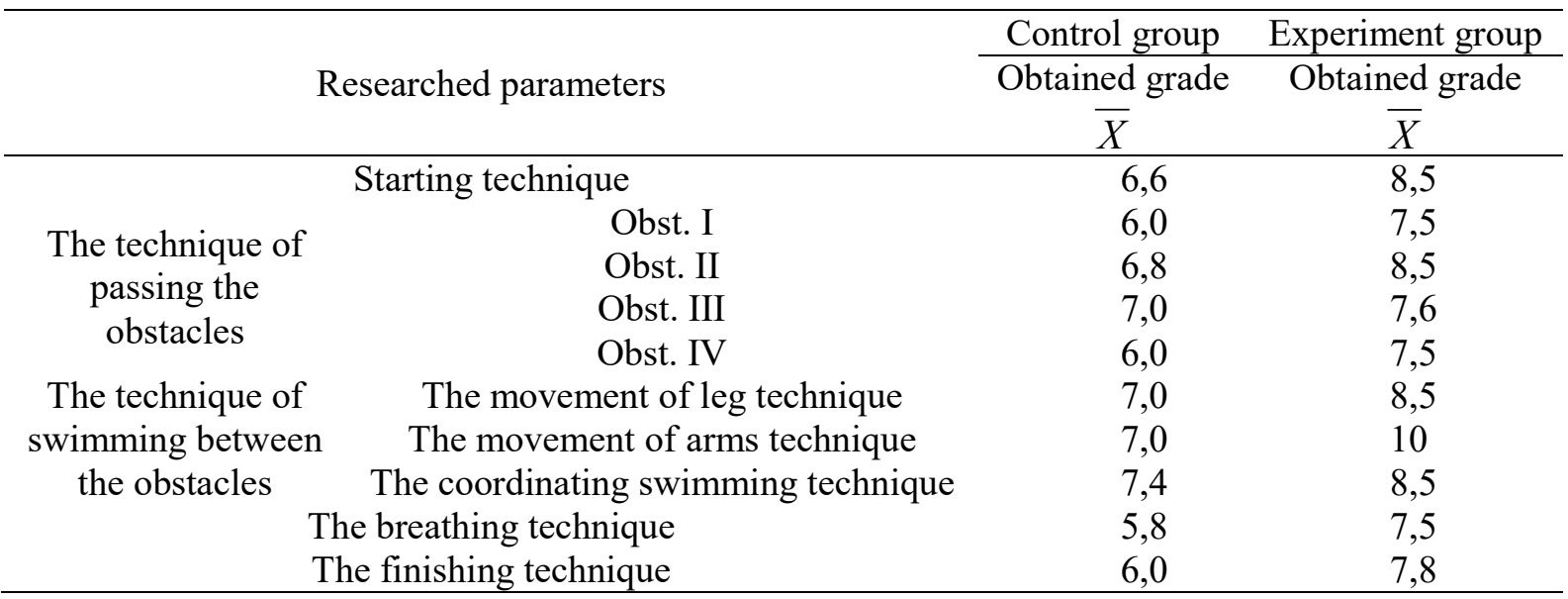


Through the specific scoring system, the experts' assessment certifies the viability of the new analytical curriculum introduced into student planning program within the experimental group. Thus, the arithmetic averages registered by the components of this group at the end of the research converge towards the veracity of the themes, objectives, tasks, methods and last but not least of the algorithmic systems specific to the $50 \mathrm{~m}$ swimming with obstacles scoring system implemented in the instructional strategy and didactic design of the military physical education.
The second test, which was approached in the study of the technical training evolution, was applied in the specific conditions of the obstacle swimming on the distance of $50 \mathrm{~m}$, contracronometer. The conditions for the development of the sample were respected in both experimental stages. The results were analyzed and statistically processed. On the basis of their processing, in the statistical analysis, the performances recorded in experimental stage 1 (initial testing) and in experimental stage 2 (final testing) were highlighted in Table no. 4.

Table no. 4

Comparative analysis of the results of experimental research (initial-final) in the testing of technical training in conditions specific to obstacle swimming on a distance of $50 \mathrm{~m}$ contracronometer

\begin{tabular}{cccc}
\hline $\begin{array}{c}\text { First experimental stage } \\
\text { (Initial testing) }\end{array}$ & \multicolumn{2}{c}{$\begin{array}{c}\text { Second experimental stage } \\
\text { (Final testing) }\end{array}$} \\
\hline \multicolumn{2}{c}{$\bar{X} \pm m$} & \multicolumn{2}{c}{$\bar{X} \pm m$} \\
\hline Control group & Experiment group & Control group & Experiment group \\
$44,00 \pm 0,52$ & $43,30 \pm 0,42$ & $40,10 \pm 0,54$ & $37,20 \pm 0,50$ \\
\hline
\end{tabular}

\section{Discussions}

According to the recorded results, if the difference in the arithmetic mean of the initial testing between the two groups is $0.70 \mathrm{sec}$. in favor of the experimental group, the final testing in experimental stage 2 is evident. Significantly significant 2.90 sec. represents the difference in arithmetic mean in favor of the experimental group. Even if the statistical significance of the difference between the averages is not calculated, from the point of view of the average performance between the two groups subjected to the research it is evident the increase of the performances obtained by the experimental group. Thus, it can be appreciated that experimental sample subjects have achieved superior results in practice. Differences in arithmetic mean to explain the concordance of performance results in this test, with the implementation of the new algorithmic system specific to the $50 \mathrm{~m}$ swim test with obstacles in the didactic technology projects elaborated in the design of the experimental instructional analytical program.

\section{Conclusions}

In the experimental research it was proved that in the testing of the technical training specific to $50 \mathrm{~m}$ obstacle swim by means of specific parameters (starting technique, obstacle crossing technique $1,2,3,4$, the technique of walking the obstacles in the crawl process, respiration technique, the finish technique), the experimental sample recorded an average of the experts' final score higher by 2.6 than the control group. At the same time, the testing of technical training in conditions specific to obstacle swimming on the $50 \mathrm{~m}$ counter chronometer distance revealed significant results at the level of the experimental group demonstrated by an increase of the performance values of 2.90 sec. to the final test of experimental stage 2 . 


\section{REFERENCES}

Chatard, J. C., Girold, S., Caudal, N., Cossor, J., \& Mason, B. (2001). Analysis of the $200 \mathrm{~m}$ events in the Sydney Olympic Games: Proceedings of swim sessions. XIX International Symposium on Biomechanics in Sports, San Francisco, CA: Blackwell J. R., Sanders R. H., 261-264.

De Mello Vitor, F., \& Silveira Böhme, M. T. (2010). Performance of young male swimmers in the 100-meters front crawl. Pediatric Exercise Science, Vol. 22, Issue 2, 278-287, Brazil: Universidade de São Paulo.

Ene-Voiculescu, V. (2003). Orientări moderne în antrenamentul sportiv din pentatlonul militar. Constanţa: Editura Academiei Navale "Mircea cel Bătrân".

Ene-Voiculescu, V., \& Ene-Voiculescu, C. (2016). Operative systems specify to the training in military pentathlon. The 22th International Scientific Conference KnowledgeBased Organization, Vol. XXII, Issue 1, DOI: 10.1515/kbo-2016-0005.

Geladas, N. D., Nassis, G. P., \& Pavlicevic, S. (2005). Somatic and physical traits affecting sprint swimming performance in young swimmers. International Journal of Sports Medicine, Vol. 26, Issue 2, 139-144, DOI:10.1055/s-2004-817862.

Lätt, E. et al. (2010). Physiological, biomechanical and anthropometrical predictors of sprint swimming performance in adolescent swimmers. Journal of Sports Science and Medicine, Vol. 9, Issue 3, 398-404.

Leblanc, H., Seifert, L., Tourny-Chollet, C., \& Chollet, D. (2007). Intra-cyclic distance per stroke phase, velocity fluctuations and acceleration time ratio of a breaststroker's hip: a comparison between elite and non-elite swimmers at different race paces. International Journal of Sports Medicine, Vol. 28, Issue 2, 140-147.

Morouco, P., Neiva, H., Gonzalez-Badillo, J. J., Garrido, N., Marinho, D. A., \& Marques, M. C. (2011). Associations between dry land strength and power measurements with swimming performance in elite athletes: a pilot study. Journal of Human Kinetics, Vol. 29A, Special Issue, 105-112.

Reis, V. M. et al. (2010). Physiological determinants of performance in breaststroke swimming events. International SportMed Journal, Vol. 11, Issue 3, 324-335.

Seifert, L., Leblanc, H., Chollet, D., \& Delignieres, D. (2010). Inter-limb coordination in swimming: effect of speed and skill level. Human Movement Sciences, Vol. 29, 103-113, Elsevier.

Strzala, M., \& Tyka, A. (2009). Physical endurance, somatic indices and swimming technique parameters as determinants of front crawl swimming speed at short distances in young swimmers. Medicina Sportivă, Vol. 13, Issue 2, 99-107, DOI: 10.2478/v10036-0090016-3. 